\title{
Accidental Dextromethorphan Ingestions in Children Less Than 5 Years Old
}

\author{
Frank LoVecchio, DOa, Anthony Pizon, MD ${ }^{b}$, Bradley Riley, MD ${ }^{b}$, Leslie Matesick, DO', \\ Sean O'Patry, DO ${ }^{d}$
}

\author{
aDepartment of Medical Toxicology, Banner Good Samaritan Medical Center, Phoenix, AZ \\ bBanner Poison Control Center, Phoenix, AZ \\ 'Maricopa Medical Center, Department of Emergency Medicine, Phoenix, AZ \\ dArizona College of Osteopathic Medicine, Glendale, AZ
}

\begin{abstract}
Introduction: The purpose of this study is to evaluate the clinical presentation of accidental dextromethorphan (DXM) ingestions in children $<5$ years old. Two consecutive years of poison center patient encounters were reviewed. Data including age, outcomes, amount of DXM ingested, co-ingestions, vital signs, clinical manifestations, hospital admissions, and mortality were abstracted. Data were analyzed using descriptive statistics.

Discussion: A total of 304 cases were identified with a mean age of 28.2 months ( $72 \%$ were $\geq 23$ months). All cases co-ingested other products of over-the-counter cough and cold medications (i.e., acetaminophen, pseudoephedrine, guaifenesin, ibuprofen, various $\mathrm{H}_{1}$ receptor antagonists, and very infrequently ethanol). The mean DXM dose ingested was $35.0 \mathrm{mg}(2.64 \mathrm{mg} / \mathrm{kg})$. Of the patients, 62 (20.4\%) experienced lethargy as the sole neurological sign and no patient had any cardiovascular abnormalities. Only 1 (13-monthold) patient, who ingested $3.2 \mathrm{mg} / \mathrm{kg}$ and presented with lethargy, was hospitalized and subsequently discharged 14 hours later. No deaths were recorded.

Conclusion: As demonstrated in our patient population, accidental ingestions of DXM in the pediatric patient did well with supportive care alone and rarely required inpatient treatment.
\end{abstract}

\section{INTRODUCTION}

Dextromethorphan (DXM) has been used as a cough suppressant for approximately 50 years. It was synthesized as an analogue of codeine with weak to no action at opioid receptors [1,2]. DXM suppresses cough by a mechanism other than opioid receptor agonism, but the complete mechanism is still unclear [1,2]. Some evidence suggests sigma receptor (no longer classified as an opioid receptor) agonism and/or NMDA-glutamate antagonism may play a role in DXM's antitussive effects $[1,2]$. The majority of DXM's clinical effects are perceived to be mediated through NMDA-glutamate receptor antagonism $[3,4]$. In overdose, these symptoms include tachycardia, hypertension, agitation, disorientation, and somnolence [5] and are similar to symptoms seen with the disassociative drugs like phencyclidine and ketamine.

The long history and frequency of DXM's use is largely due to its impeccable safety profile, despite recent research suggesting it is a poor antitussive $[6,7]$. Unlike opiates, at therapeutic doses

Keywords: Dextromethorphan, pediatrics, ingestion

Note: There was no outside funding of any kind used for this study.

Corresponding Author: Frank LoVecchio, DO, Department of Emergency Medicine, Medical Director Banner Good Samaritan Regional Poison Center Research Director, Maricopa Medical Center., Phoenix, AZ, 85006 Email: Frank.LoVecchio@bannerhealth.com 
DXM causes little sedation, respiratory depression, or hemodynamic side effects [1]. These same characteristics have led to the ubiquity of this drug in cough and cold preparations alone and in combination with other medications, and these products may fall into the hands of a toddler. Clinical experience treating misadventures of DXM abuse are growing [5,8,9], yet little has been published concerning accidental ingestions in the pediatric population. The purpose of this research is to describe the clinical presentation and outcome of accidental pediatric ingestions of DXM in children $<5$ years old.

\section{METHODS}

A retrospective chart review of DXM ingestions reported to our poison center during 2003 and 2004 was conducted. Search via the charts was conducted using CrystalReports and Microsoft Word (Bellevue, WA). The reviewers received standardized training in systematic chart review, and a standardized data collection sheet was completed. After a trial of 3 "practice" charts and a review, the reviewers were allowed to complete the chart review. Data including age, outcomes, amount of DXM ingested, coingestions, vital signs, clinical manifestations, hospital admissions, and mortality were abstracted. Data was analyzed using Excel (Bellevue, WA) and STATA software. All data was reviewed by a third investigator, and a kappa score was calculated.

The inclusion criteria for this study consisted of accidental ingestions of DXM as reported to the poison center. All patients under the age of 5 years, regardless of the amount ingested, were included.

In addition to these criteria, poison center follow-up occurred until a final outcome was documented. Specifically, all patients were followed by the poison center until the cessation of symptoms or for a minimum of 24 hours.

\section{RESULTS}

Approximately 110,000 charts were searched using software programs mentioned in the methods section for the keyword "dextromethorphan," its numerical code and age $\leq 5$ years old. A total of 304 cases were identified that met the inclusion criteria.

The mean age was 28.2 months ( $72 \%$ were $\geq 23$ months). All cases co-ingested other products of over-the-counter cough and cold medications. Co-ingestants included acetaminophen, pseudoephedrine, guaifenesin, ibuprofen, and various $\mathrm{H}_{1}$ receptor antagonists. The approximate amount of DXM ingested was documented in 282 cases and found to have a mean of $35.0 \mathrm{mg}$ (or $2.64 \mathrm{mg} / \mathrm{kg}$ ). No patients demonstrated any hemodynamic instability (low blood pressure or tachycardia requiring an intervention) and only $62(20.4 \%)$ demonstrated signs of sedation. No other neurological abnormalities were noted in any patient. No patients required treatment for any co-ingestants (i.e., n-acetylcysteine for acetaminophen ingestion). No deaths were recorded. Only 1 patient, a 13-month-old, was admitted after presenting with prolonged lethargy. By history, the child had ingested
$3.2 \mathrm{mg} / \mathrm{kg}$ and was admitted for 14 hours, after which time she was discharged home and was neurologically normal.

A kappa score for inter-reviewer reliability was $0.74,95 \% \mathrm{CI}$ [0.61-0.81].

\section{DISCUSSION}

A published report indicates that a trend toward increased DXM abuse exists [5,9]. Increased clinical experience with DXM abuse has brought heightened awareness for its toxicity [3-5]. Baker and colleagues published a case series demonstrating that symptoms from intentional DXM ingestion include tachycardia (50\%), somnolence $(24.4 \%)$, hypertension (16.7\%), agitation (12.8\%), and disorientation (10.3\%), among others [5]. Other case reports have demonstrated deaths from either intentional abuse or accidental pediatric ingestion $[8,10]$. Despite growing knowledge concerning intentional supratherapeutic misadventures, little objective evidence is available on the clinical presentation and outcomes of pediatric patients who accidentally ingest DXM. Yet, the potential for accidental ingestions is high due to the prevalence of DXM's use in cough and cold medications.

This study reaffirms the long safety record of DXM. Most children who accidentally ingest DXM have minor clinical effects and rarely require hospitalization. Plus, the amount of co-ingested medications is low enough as to not require treatment other than supportive care alone.

A limitation of this study is its reliance on patient history for amount and type of drug ingested, and no confirmatory levels were obtained. This study was based solely on data collected from one poison-control center; hence, it was limited to those residing in this region. When reproducing this study, it would be advantageous to include multiple poison control centers in order to sample various populations. Poison center data is limited by referral and recording bias.

\section{CONCLUSION}

Despite growing experience treating intentional ingestions of DXM, little is known about accidental pediatric ingestions. In our cohort, only 1 patient was hospitalized and no deaths occurred. As demonstrated in our patient population, accidental ingestions of DXM in this pediatric patient did well with supportive care alone and rarely require inpatient treatment.

The authors have no potential financial conflicts of interest to report.

\section{REFERENCES}

1. Weinbroum AA, Rudick V, Paret G, Ben-Asraham R. The role of dextromethorphan in pain control. Can J Anesth 2000;47:585-596.

2. Brown C, Fezoui M, Selig WM, Schwartz CE, Ellis JL. Br J Pharmacol 2004;141:233-240. 
3. Kirages TJ, Harxh PS, Mycyk MB. Severe manifestations of Coricidin intoxication. Am J Emerg Med 2003;21:473-475.

4. Wolfe TR, Caravati EM. Massive dextromethorphan ingestion and abuse. J Emerg Med 1995;13:174-176.

5. Baker SC, Borys DJ. A possible trend suggesting increased abuse from Coricidin exposures reported to the Texas Poison Network: comparing 1998 to 1999. Vet Hum Toxicol 2002;44: 169-171.

6. Paul IM, Shaffer ML, Yoder KE, Sturgis SA, Baker MS, Berlin CM. Dose-responsive relationship with increasing doses of dextromethorphan for children with cough. Clin Ther 2004; 26:1508-1514.
7. Lee PCL, Jawad MS, Eccles R. Antitussive efficacy of dextromethorphan in cough associated with acute upper respiratory tract infection. J Pharm Pharmacol 2000;52:1137-1142.

8. Chung H, Park M, Hahn E, Choi H, Choi H, Lim M. Recent trends of drug abuse and drug-associated deaths in Korea. Ann N Y Acad Sci 2004;1025:458-464.

9. Murry S, Brewerton T. Abuse of over-the-counter dextromethorphan by teenagers. South Med J 1993;86: 1151-1153.

10. Boland DM, Rein J, Lew EO, Hearn WL. Fatal cold medication intoxication in an infant. J Anal Toxicol 2003;27: 523-526. 